\section{IMIGRANTES, TRABALHO E CAFÉ}

Immigrants, work and coffee

RESENHA de BASSANEZI, Maria Sílvia Beozzo. Colonos do Café. São Paulo: Contexto, 2019. 320p.
Maisa Faleiros da

\section{CUNHA}

(D) maisa@nepo.unicamp.br

Universidade

Estadual de Campinas

Campinas, SP, Brasil

A leitura do livro Colonos do Café é fluida e agradável. De imediato, é como se o leitor entrasse num túnel do tempo e espiasse a vida de trabalhadores e trabalhadoras na faina do café em uma fazenda paulista no tempo de dantes, parafraseando Maria Paes de Barros (1998).

O trabalho em uma propriedade rural modelo, a fazenda Santa Gertrudes, é o eixo central da obra. Os números e valores referentes ao montante de trabalhadores e à produção cafeeira da fazenda são significativos e justificam, por si só, uma análise pormenorizada. No entanto, o que nos deparamos é com uma pesquisa acurada e meticulosa dos trabalhadores que formaram o complexo e diverso universo da fazenda. À dura labuta de sol a sol de muitos homens e mulheres envolvidos na produção cafeeira, é possível vislumbrar, ademais, a história e as particularidades da fazenda, informações sobre a produção cafeeira e as múltiplas experiências cotidianas de seus colonos. 
A esclarecedora introdução e os sete capítulos da obra iniciam-se com fragmentos de histórias de homens, mulheres, crianças, jovens, adultos e velhos que passaram pela propriedade ou viveram em suas terras e labutaram em suas lavouras. Mais precisamente, Maria Sílvia Beozzo Bassanezi analisa uma rica e bem conservada documentação do período de 1895 a 1930. Os documentos produzidos pela administração da fazenda foram, a princípio, objeto de escrutínio da autora para a realização de sua tese de doutorado defendida em 1974. Durante a realização dessa pesquisa, entre os anos de 1969 a 1973, foram coletados depoimentos orais de antigos trabalhadores da fazenda, de ex-funcionários e dos proprietários.

Ao longo dos últimos 45 anos, a pesquisadora do Núcleo de Estudos de População "Elza Berquó" (NEPO/UNICAMP) deu continuidade ao levantamento de fontes e aprofundou suas pesquisas sobre o universo dos colonos e imigrantes italianos, com vasta produção acadêmica sobre o tema e, em boa parte, incorporadas ao livro. Como atesta a autora, trata-se de um trabalho que "incorpora novos olhares e análises sobre as fontes originalmente trabalhadas" (BASSANEZI, 2019, p. 19).

Conhecemos, no decorrer das páginas, as trajetórias de Ângelo, Felice, Guiseppe, Ângela, Francesco, Eugenio, Luigi e muitos outros e outras, representativas das vivências de trabalhadores do café e resgatadas graças ao trabalho meticuloso de cruzamento de informações presentes em fontes nominativas como documentos da fazenda, registro paroquial de batismo e registro civil de casamento e óbito.

No painel erguido com as trajetórias de famílias imigrantes destacam-se as italianas (principal grupo que se dirigiu à fazenda) e, em menor número, as austríacas, as portuguesas e as espanholas que se somaram às brasileiras (inclusive afrodescendentes que permaneceram nas terras da fazenda após a abolição da escravidão em 1888).

Unindo a micro-história, a partir de um caso exemplar, à perspectiva macro que considera os contextos paulista, brasileiro e internacional, a autora apresenta o cenário e os condicionantes que culminaram com a chegada de aproximadamente 2,2 milhões de imigrantes, sobretudo italianos, a São Paulo entre meados dos anos 1880 e 1930 (BASSANEZI, 2019, p. 16).

A fazenda de Santa Gertrudes' ${ }^{1}$ como referida na documentação da época, integrou originalmente o município de Rio $\mathrm{Claro}^{2}$, localizado na região conhecida como Velho Oeste Paulista, a mais próspera e dinâmica área da economia brasileira em fins do século XIX e começo do XX. Esse dinamismo foi impulsionado pela expansão cafeeira vivenciada pela província e, posteriormente, estado de São Paulo a partir da segunda metade do século XIX.

Como outras propriedades cafeeiras, a fazenda Santa Gertrudes foi o destino de diversas famílias imigrantes naturais do norte da Itália, região do Vêneto. A motivação econômica, a crise pós unificação italiana, a miséria e o sonho de se tornarem proprietários de terras na América impulsionaram a emigração oceânica, mas como a autora chama a atenção, fatores socioculturais também devem ser considerados para a decisão de partir. Dentre os possíveis motivos, destacam-se a ameaça de valores e costumes ligados ao trabalho familiar e ao modo de vida pautado pela religiosidade. 
Dessa forma, "a emigração era vista também como uma forma de preservar tais valores, já que os imigrantes acreditavam poder manter suas tradições e costumes no sistema de trabalho e no modo de vida que os aguardavam além-mar" (BASSANEZI, 2019, p. 15).

A lavoura de café demandava grande quantidade de mão de obra. A fazenda Santa Gertrudes chegou a ter, em determinados períodos, uma população trabalhadora de 1.500 pessoas e 150 famílias colonas que se dividiam em oito colônias identificadas pelo nome de um santo da Igreja Católica (São Joaquim, Santo Antônio, etc.). A área total da propriedade alcançou 1.356 alqueires ${ }^{3}$ entre 1897 e 1921. A extensa propriedade abrigava cafezais, cujo número de cafeeiros "variou de, aproximadamente, 800 mil a quase um milhão de pés e colheita anual de cerca de 80 mil alqueires"4 (BASSANEZI, 2019, p. 38). Além do café, principal atividade da fazenda, matos, áreas de pastagens e invernada dividiam espaço com roças de alimentos (arroz, milho, feijão, hortaliças e pomares).

O proprietário Eduardo Prates ostentava o título de conde de Prates (concedido pelo papa Leão XIII), era um capitalista que vivia na cidade de São Paulo e dirigia a fazenda por meio de um administrador. "Seu contato com a administração da fazenda era contínuo e ininterrupto, mantido por meio da correspondência diária que viajava via trem" (BASSANEZI, 2019, p. 53). É possível constatar as modernidades que chegaram à Santa Gertrudes no começo do século XX (mobiliário requintado na sede da fazenda, luz elétrica, linha telefônica, cinematógrafo) oriundas da expansão do capitalismo, de melhorias dos meios de transporte e de comunicação que, por sua vez, ampliaram o acesso aos bens e aos luxos que os lucros do café podiam pagar.

Na fazenda Santa Gertrudes, os imigrantes italianos eram estimulados pela administração local a convidar parentes e amigos para emigrarem. A travessia do oceano Atlântico, a chegada ao porto de Santos, a vinda de trem para a Hospedaria dos Imigrantes no bairro do Brás na cidade de São Paulo e, de São Paulo, e novamente de trem, o percurso até as fazendas cafeeiras do Oeste paulista foi o trajeto de boa parte das famílias imigrantes retratadas.

Instaladas na fazenda Santa Gertrudes, as famílias sem recursos logo recorriam ao crédito fornecido pelo proprietário para consumir os produtos vendidos no armazém local. Apesar da vigilância exercida pela administração, não foi possível impedir a fuga de famílias endividadas, a saída daquelas insatisfeitas ou que se mudaram para outras propriedades mais atrativas ao fim do ano agrícola (em outubro, quando se encerrava a colheita), momento de grande mobilidade de trabalhadores entre as propriedades.

Ao chegarem ao Brasil, as famílias vindas da Europa eram relativamente jovens, em plena fase produtiva e reprodutiva, compostas em sua maioria só por casal ou por casal com filhos solteiros e pequenos. A fazenda Santa Gertrudes dava preferência aos italianos e cerca de dois terços de seus colonos entre 1909-1918 eram daí originados. Assim como os demais trabalhadores, as famílias italianas trabalhavam sob o regime de colonato.

O termo "colono designava não apenas o trabalhador isolado, mas também todo seu grupo familiar” (BASSANEZI, 2019, p. 79). Ao contratar o colono, o fazendeiro 
contratava o trabalho de todos os elementos da família. No tocante à cafeicultura paulista, "colono" e "família colona" são sinônimos. O número de pés de café sob a responsabilidade do colono era estipulado em contrato estabelecido com a fazenda e atribuído de acordo com o número de membros da família colona aptos ao trabalho ("pessoas de trabalho"). Os termos do contrato de trabalho favoreciam o proprietário, a quem era permitido aplicar multas e demitir o trabalhador quando e como lhe aprouvesse.

Dada a complexidade da cultura do café, a fazenda Santa Gertrudes se situava como uma grande empresa agrícola capitalista. A obra esmiúça as diversas etapas do processo de produção, tais como a preparação da terra, plantio e manutenção da lavoura cafeeira; o beneficiamento do grão, o escoamento da produção; as necessidades e ofícios para a manutenção da fazenda, a gama de trabalhadores empregados e os ganhos dos colonos no trato do cafeza/ ${ }^{5}$. Na época da colheita, toda a família colona participava e os rendimentos eram mais elevados. A documentação permite acompanhar as economias, os valores que alguns colonos conseguiram acumular em bancos de São Paulo, resultantes dos diferentes momentos de atividades na fazenda. Alguns poucos, após pouparem uma vida inteira, realizaram o sonho de se tornar proprietário de terras.

Ao abordar aspectos da vida diária como a rotina do trabalho, a casa, a roupa, a refeição, o lazer, a religião e a escola, a autora, de maneira criativa, destrincha as características práticas e culturais de elementos da vida privada e do cotidiano dos colonos, como neste exemplo: "a roupa, que protege o corpo e preserva os costumes" (BASSANEZI, 2019, p. 141).

A obra traz um quadro apurado da dura jornada de trabalho das famílias colonas que se estendida do nascer do sol ao final do entardecer. "Durante todo o ano, essa jornada era cumprida rigorosamente, sob a vigilância do diretor ou fiscal da colônia. Às cinco horas da manhã todos já estavam acordados. Às seis horas, eram chamados pelos sinos tocados em todas as colônias" e, então, partiam para mais um dia no cafezal (BASSANEZI, 2019, p. 131). Assim, a disciplina do trabalho era mantida por meio da presença de fiscais de turma que estavam sob a vigilância do administrador.

Além de descrever as condições duras de trabalho, Bassanezi direcionou o olhar para o espaço doméstico lançando luz sobre as relações familiares, étnicas, de gênero e geracionais estabelecidas entre os imigrantes, suas famílias e outros indivíduos.

As relações familiares traziam características patriarcais do país de origem que pouco se diferenciaram das aqui encontradas, a divisão de tarefas era rígida e o trabalho doméstico era atribuído às mulheres, assim como o cuidado de crianças, idosos e inválidos. Ao pai e chefe da casa cabia a palavra final sobre as tarefas de trabalho e as decisões da família.

Depoimentos coletados de ex-colonas dão conta de que as mulheres trabalhavam até a hora de parir, relatando casos de crianças que chegaram a nascer na carroça enquanto suas mães tentavam voltar para casa. Em outras situações, mais raras, os 
bebês nasciam sob a sombra do cafeeiro e eram colocados em caixote forrado com alguns panos que a gestante previdente levava ao cafezal (BASSANEZI, 2019, p. 134).

Milhares de crianças nasceram, foram batizadas e, uma parte delas, faleceram na fazenda Santa Gertrudes. A família se constituía por meio do casamento formal, "de papel passado" no cartório e cerimônia na igreja. Assim, as atas de batismo atestam que as crianças filhas de italianas eram todas legítimas. Com base em cálculos indiretos, a taxa de fecundidade total das mulheres italianas de 15 a 49 anos foi estimada em 7,1 filhos nascidos vivos, em média. $O$ batismo se mostrou uma forma de estabelecer ou fortalecer laços de compadrio entre os pais do batizando, vizinhos, amigos e parentes.

A massiva presença da religião católica garantiu forte coesão e homogeneidade cultural entre os imigrantes da fazenda. Como afirma a autora, o "exclusivismo católico foi muito rígido na fazenda Santa Gertrudes” (BASSANEZI, 2019, p. 161).

Esta condição era garantida graças às regalias concedidas pela Santa Fé ao proprietário, conde Prates (BASSANEZI, 2019, p. 151-152). A fazenda possuía uma Capela lateranense, subordinada à Igreja de São João de Latrão de Roma, onde eram celebradas missas aos domingos, os colonos contavam com a presença de padres e cerimônias religiosas com mais frequência que outras áreas rurais do Brasil. As pregações religiosas eram em italiano, o que permitia ao padre atuar como um elemento disciplinador na fazenda.

A maioria dos colonos do café era analfabeta ou semianalfabeta. Apesar disso, muitos se esforçaram para garantir que seus filhos aprendessem a ler e escrever, mas a primeira escola pública foi instalada na fazenda somente em 1921 (BASSANEZI, 2019, p. 164).

A mortalidade atingiu, principalmente, as crianças de até 4 anos. O tétano ("mal de sete dias") e os problemas gastrointestinais foram os principais responsáveis pela elevada mortalidade infantil (óbitos de menores de um ano por mil nascidos vivos), refletindo as más condições sanitárias e de assistência à saúde a que os trabalhadores e suas famílias estavam submetidos.

Como bem destacado no livro, é possível afirmar que as experiências das famílias sob o colonato na fazenda Santa Gertrudes não devem se diferenciar do que ocorria em outras fazendas cafeeiras, pelo menos as localizadas no Velho Oeste Paulista. Estudos como Colonos do Café esmiúçam o trabalho e a vida rural do interior do Brasil que ficou no tempo de dantes, mas que permanecem presentes na história de gerações de brasileiros e, ainda hoje, influenciam mentalidades e comportamentos.

O estudo dos trabalhadores de uma fazenda modelo de forma detalhada e minuciosa foi possível graças à rica documentação produzida pela administração da fazenda, preservada e mantida em bom estado de conservação, situação relativamente rara para os documentos privados no Brasil.

É importante ressaltar que além da leitura instigante e, por vezes, tocante que o texto nos proporciona, a presença de material iconográfico e fotográfico nos permite visualizar as gentes, paisagens e espaços da fazenda Santa Gertrudes. 
Certamente para facilitar a leitura, os quadros informativos, dados quantitativos e detalhamento de informações citadas ao longo do livro foram apresentadas no tópico "Anexos". Neste último item, é possível ao leitor mais curioso ou que queira informações mais aprofundadas, conferir a descrição das fontes, ter acesso aos documentos referentes à vida religiosa, ao trabalho, ganhos e despesas das famílias colonas, quadros com a produção de café, dados sobre o patrimônio da fazenda e tabelas e gráficos com informações sobre a origem dos imigrantes, casamentos, batismos, nominação, apadrinhamento e óbitos.

Colonos do café combina a leveza do texto literário com o rigor técnico-científico de um estudo acadêmico. A autora não deixa de cotejar suas conclusões com a bibliografia nacional e internacional especializada, mas o faz de forma clara, objetiva e acessível. Seguramente é uma obra com todas as qualidades para extrapolar os muros universitários, estendendo-se aos interessados em aprofundar um pouco mais sobre a história da cafeicultura em São Paulo e da imigração internacional, em especial, a italiana durante a primeira República.

\section{Referências}

BASSANEZI, Maria Sílvia Beozzo. Colonos do Café. São Paulo: Contexto, 2019.

BARROS, Maria Paes de. No tempo de dantes. São Paulo: Paz e Terra, 1998 [1946].

\section{Notas}

1 A autora optou por nomeá-la Fazenda Santa Gertrudes, como é conhecida atualmente (BASSANEZI, 2019, p. 63).

2 A fazenda Santa Gertrudes "pertenceu a Rio Claro até 1948, quando passou a integrar o recém-criado município de Santa Gertrudes” (BASSANEZI, 2019, p. 18).

3 "O alqueire paulista para área corresponde a 24.200 metros quadrados" (BASSANEZI, 2019, p. 24).

4 Segundo cálculos da autora, "um alqueire (50 litros) produz 0,59 arrobas de café limpo" (BASSANEZI, 2019, p. 292).

5 "Trabalho que consistia em fazer a limpeza das ervas daninhas ("carpir") de três a cinco vezes ao ano, adubar os cafeeiros, replantar as falhas, cortar galhos secos e quebrados, e também colher os grãos de café - mediante pagamento predefinido em dinheiro" (BASSANEZI, 2019, p. 79).

Maisa Faleiro da CUNHA. Pesquisadora do Núcleo de Estudos de População "Elza Berquó" (NEPO) da Universidade Estadual de Campinas (UNICAMP). Possui graduação em Ciências Sociais (2002) pela UNICAMP, mestrado em Demografia (2005) pela UNICAMP e doutorado em Demografia (2009) pela UNICAMP. Pósdoutora pela Faculdade de Economia, Administração e Contabilidade da Universidade de São Paulo (FEA-USP). Tem experiência na área de Demografia e História atuando principalmente nos seguintes temas: história da população, histórica econômica, demografia da escravidão e família escrava. Coordenadora Associada do Nepo e coordenadora do GT População e História da Associação Brasileira de Estudos Populacionais (ABEP). 